\title{
Rapid Endocytosis Does Not Recycle Vesicles within the Readily Releasable Pool
}

\author{
Xin-Sheng Wu and Ling-Gang Wu \\ Synaptic Transmission Section, National Institute of Neurological Disorders and Stroke, Bethesda, Maryland 20892
}

\begin{abstract}
Endocytosis is essential in maintaining exocytosis at secretory cells. Rapid endocytosis with a time course less than a few seconds is widely observed at nerve terminals and non-neuronal secretory cells. It is generally assumed that rapid endocytosis recycles vesicles within the readily releasable pool (RRP) via a kiss-and-run mechanism that involves rapid opening and closure of a fusion pore at the release site. The present work suggests that both rapid ( $\tau$ less than $\sim 2 \mathrm{~s}$ ) and slow $(\tau=\sim 10-20 \mathrm{~s})$ endocytosis do not recycle vesicles to the RRP but to a recycling pool at least a few times larger than the RRP at a nerve terminal, the calyx of Held in rat brainstem. Challenging the long-held view that rapid endocytosis offers a rapid, local vesicle recycling within the RRP, our finding calls for reconsideration of the function and the underlying mechanism of rapid endocytosis. We suggest that rapid endocytosis provides the nerve terminal the ability to recycle vesicles rapidly via the recycling pool and to maintain the normal morphology of the nerve terminal, including the release site, by rapidly clearing the fused vesicle membrane from the release site during intense firing.
\end{abstract}

\section{Introduction}

Vesicle fusion is followed by vesicle endocytosis, which forms new vesicles. Recycling of newly formed vesicles is crucial in maintaining synaptic transmission. Studies in the last two decades revealed that endocytosis can be rapid ( $\tau$ less than $\sim 2 \mathrm{~s}$ ) or slow $(\tau=\sim 10-30 \mathrm{~s})(\mathrm{Wu}, 2004)$. Slow endocytosis has been observed at every secretory cell and synapse examined $(\mathrm{Wu}$, 2004). Similarly, rapid endocytosis has been observed with whole-cell capacitance measurements at various types of nerve terminals and non-neuronal secretory cells in various stimulation conditions. These cell types include ribbon-type synapses containing clear-core vesicles (von Gersdorff and Matthews, 1994), large calyx-type synapses containing conventional active zones and clear-core vesicles (Sun et al., 2002), pituitary nerve terminals that secrete vesicles to the blood vessels (Hsu and Jackson, 1996), hippocampal mossy fiber terminals (Hallermann et al., 2003), and various types of non-neuronal secretory cells containing large dense-core vesicles, such as chromaffin cells (Artalejo et al., 1995) and pancreatic $\beta$ cells (He et al., 2008).

What is the functional difference between rapid and slow endocytosis? Slow endocytosis, mediated by a classical, clathrindependent mechanism (Granseth et al., 2006), is generally assumed to follow full collapse fusion and recycle vesicles to the recycling or reserve pool. Rapid endocytosis has long been assumed to reflect kiss-and-run, which involves rapid fusion pore opening and closure at the same site and, by definition, recycles

\footnotetext{
Received May 19, 2009; revised July 9, 2009; accepted July 24, 2009.

This work was supported by the National Institute of Neurological Disorders and Stroke Intramural Research Program. We thank Drs. Benjamin Mcneil and Jianhua Xu for comments on this manuscript.

Correspondence should be addressed to Ling-Gang Wu, Synaptic Transmission Section, National Institute of Neurological Disorders and Stroke, 35 Convent Drive, Building 35, Room 2B-1012, Bethesda, MD 20892. E-mail: wul@ninds.nih.gov.

D0I:10.1523/JNEUROSCI.2367-09.2009

Copyright $\odot 2009$ Society for Neuroscience $\quad$ 0270-6474/09/2911038-05\$15.00/0
}

vesicles within the readily releasable pool (RRP) of vesicles (Fesce et al., 1994). Surprisingly, these important assumptions have not been experimentally tested.

The cell-attached capacitance recordings have revealed the existence of kiss-and-run in non-neuronal secretory cells, pituitary nerve terminals, and the calyx of Held (Albillos et al., 1997; Klyachko and Jackson, 2002; He et al., 2006). Clearly, kiss-andrun involves rapid endocytosis. However, whether rapid endocytosis results from kiss-and-run is unclear.

Optical measurements also suggest the existence of rapid kissand-run at conventional synapses, particularly the cultured hippocampal synapse (Aravanis et al., 2003; Zhang et al., 2009), although there is an intense debate as to whether rapid kiss-andrun exists at conventional synapses ( $\mathrm{He}$ and $\mathrm{Wu}, 2007)$. It has been proposed that kiss-and-run locally recycles vesicles within the RRP at cultured hippocampal synapses (Pyle et al., 2000). This proposal was further supported by a recent study that loaded the vesicles with a large $\mathrm{pH}$-sensitive quantum dot at cultured hippocampal synapses (Zhang et al., 2009), although whether the large quantum dot inside the vesicle affects the fusion mode is not well understood.

Here, we determined whether the widely observed rapid endocytosis recycles vesicles within the RRP at calyces. Surprisingly, our results suggest that both rapid and slow endocytosis do not recycle vesicles within the RRP, which calls for reconsideration of the function and the underlying mechanism of rapid endocytosis.

\section{Materials and Methods}

Methods for preparing brainstem slices from Wistar rats (7-10 d old) and measurements of $\mathrm{Ca}^{2+}$ currents and capacitance from the calyx of Held in the medial nucleus of the trapezoid body are described previously (Sun and Wu, 2001; Sun et al., 2004). Wistar rats were decapitated. Parasagittal slices of $200 \mu \mathrm{m}$ thick were cut from the auditory brainstem with a vibratome. Recordings were made at room temperature $\left(22-24^{\circ}\right)$ in a solution that pharmacologically isolated $\mathrm{Ca}^{2+}$ currents. This solution 


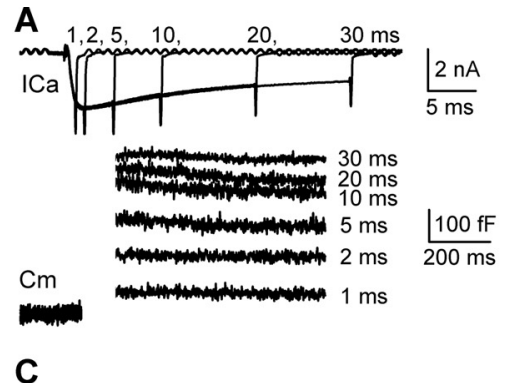

E
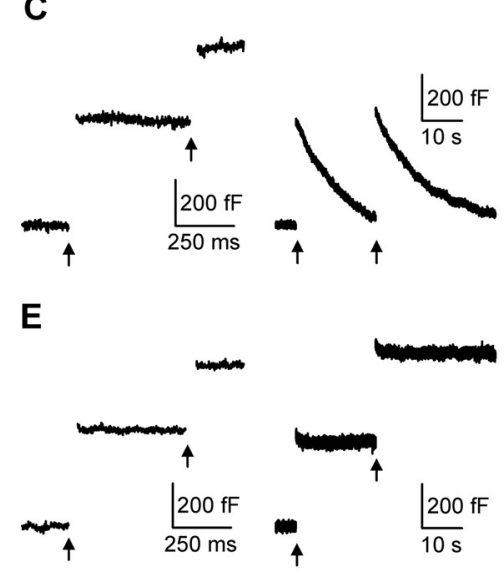
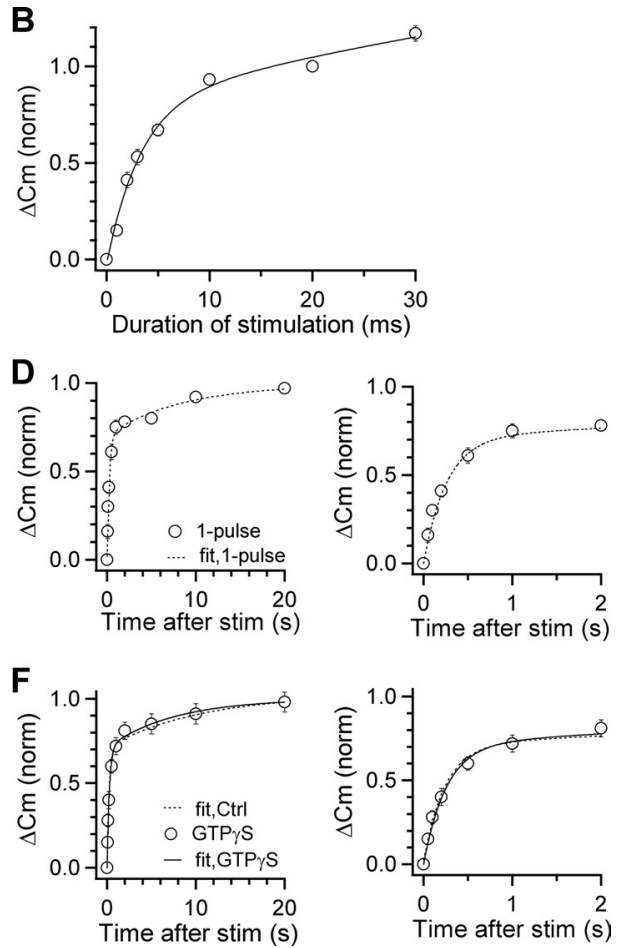

statistical tests used here were $t$ test. Measurements of the RRP size and the RRP replenishment time course are described in supplemental information I, available at www.jneurosci.org as supplemental material.

\section{Results}

\section{Definition of the RRP at the calyx}

To determine whether endocytosis recycles vesicles within the RRP, the RRP should be experimentally defined. Two pieces of evidence indicated that a $10-20$ ms depolarization (from -80 to $+10 \mathrm{mV}$, if not mentioned) depleted the RRP at the calyx. First, the vesicle pool depleted by a 10-20 ms depolarization is the same as that depleted by 20 action potentialequivalent stimuli (AP-e, 1 ms depolarization from -80 to $+7 \mathrm{mV}$ ) at $100-300 \mathrm{~Hz}$ (Sun et al., 2002). Second, release is increased as the length of depolarization increased from 1 to $10 \mathrm{~ms}$, whereas further increase of the depolarization length from 10 to $20 \mathrm{~ms}$ does not cause much further increase of release (Fig. $1 A, B$ ) (Sun and $\mathrm{Wu}, 2001$; Taschenberger et al., 2002). A $20 \mathrm{~ms}$ depolarization induced a capacitance jump $\left(\Delta C_{\mathrm{m}}\right)$ of $459 \pm 29 \mathrm{fF}$ $(n=28)$. The $\Delta C_{\mathrm{m}}$ induced by $1-30 \mathrm{~ms}$ depolarization, when normalized to that evoked by a $20 \mathrm{~ms}$ depolarization at the same calyx, was fitted well with a biexponential function:

$$
\begin{aligned}
\Delta C_{\mathrm{m}}=A_{1}[ & \left.1-\exp \left(-t / \tau_{1}\right)\right] \\
& +A_{2}\left[1-\exp \left(-t / \tau_{2}\right)\right],
\end{aligned}
$$

where $A_{1}=0.83, \tau_{1}=3.2 \mathrm{~ms}, A_{2}=1.3$, $\tau_{2}=99 \mathrm{~ms}$ (Fig. $1 A, B$ ). Thus, there was a contained (in mM) $105 \mathrm{NaCl}, 20$ TEA-Cl, $2.5 \mathrm{KCl}, 1 \mathrm{MgCl}_{2}, 2 \mathrm{CaCl}_{2}, 25$ $\mathrm{NaHCO}_{3}, 1.25 \mathrm{NaH}_{2} \mathrm{PO}_{4}, 25$ dextrose, 0.4 ascorbic acid, 3 myo-inositol, 2 sodium pyruvate, 0.001 tetrodotoxin, 0.1 3,4-diaminopyridine, 0.05 D-APV, pH 7.4 when bubbled with $95 \% \mathrm{O}_{2}$ and $5 \% \mathrm{CO}_{2}$.

The calyx was whole-cell voltage clamped with a pipette (3.5-5 M $\Omega$ ) containing (in mM) 125 Cs-gluconate, $20 \mathrm{CsCl}, 4 \mathrm{MgATP}, 10 \mathrm{Na}_{2}$ phosphocreatine, 0.3 GTP, 10 HEPES, 0.05 BAPTA, pH 7.2, adjusted with $\mathrm{CsOH}$. The osmolarity of the pipette solution was maintained between 310 and 325 mOsm by slightly adjusting Cs-gluconate concentration. For some experiments (Figs. 1E,F, 2E,F), GTP was replaced with GTP $\gamma \mathrm{S}(0.3 \mathrm{~mm})$.

Calyces visible under the differential interference contrast microscope were selected for capacitance recordings regardless of whether they were connected with a short or long axon, because similar results were obtained from capacitance measurements in calyces connected with a short or long axon (Sun et al., 2004). The capacitance was measured with the EPC-9 amplifier together with the software lock-in amplifier (PULSE, HEKA). The series resistance was compensated by $60 \%$. A sinusoidal stimulus was applied in addition to the constant holding potential $(-80$ $\mathrm{mV}$ ). The peak-to-peak voltage of the sine wave was $<60 \mathrm{mV}$ to avoid activation of $\mathrm{Ca}^{2+}$ currents (Borst et al., 1995; Wu et al., 1998). The resulting current was processed using the Lindau-Neher technique (Lindau and Neher, 1988; Gillis, 1995) to give estimates of the membrane capacitance, membrane conductance, and the series conductance. The sine wave frequency was $1000 \mathrm{~Hz}$. The reversal potential of the measured DC current was assumed to be $0 \mathrm{mV}$ (Gillis, 1995), although changing the reversal potential did not significantly change the capacitance value (Sun and $\mathrm{Wu}, 2001)$. Data were expressed as mean \pm SEM. Unless mentioned, fast and a slow component of release. With a $10-20 \mathrm{~ms}$ depolarization, the slow release component was only $\sim 14-22 \%$ of total release. This value should be at least $\sim 5 \%$ smaller, if we subtract the vesicle mobilization during 10-20 ms depolarization (supplemental information II, available at www.jneurosci.org as supplemental material). We concluded that a 10-20 ms depolarization depleted the RRP, in which the fast release component was dominant (see supplemental information II for additional discussion, available at www.jneurosci.org as supplemental material).

\section{Slow endocytosis does not recycle vesicles within the RRP}

To determine whether slow endocytosis recycle vesicles within the RRP, we induced slow endocytosis with a $20 \mathrm{~ms}$ depolarization (Wu et al., 2005). The capacitance jump after a $20 \mathrm{~ms}$ depolarization decayed monoexponentially with a slow $\tau$ of $12.5 \pm 1.2 \mathrm{~s}$ $(n=12)$ (Fig. 1C) (Sun and $\mathrm{Wu}, 2001)$. Two pieces of evidence suggest that slow endocytosis did not recycle vesicles within the RRP. First, we measured the RRP replenishment time course by applying a testing $20 \mathrm{~ms}$ depolarization at various intervals $(\Delta t=$ $0.05-20 \mathrm{~s}$ ) after the conditioning $20 \mathrm{~ms}$ depolarization. The capacitance jump induced by the testing $20 \mathrm{~ms}$ depolarization, which reflected the RRP replenishment, could be fitted with Equation 1 with $A_{1}=0.71, \tau_{1}=0.26 \mathrm{~s}, A_{2}=0.29, \tau_{2}=9.5 \mathrm{~s}$ 
(Fig. 1C,D; see also supplemental information III, available at www.jneurosci. org as supplemental material), similar to previous reports (Wu and Borst, 1999; Sakaba and Neher, 2001; Sun and Wu, 2001). Clearly, the slow endocytosis time course is different from and slower than the RRP replenishment time course, indicating that the RRP replenishment is mainly not caused by slow endocytosis. Second, we blocked endocytosis by replacing GTP with GTP $\gamma \mathrm{S}(0.3 \mathrm{~mm})$ in the pipette solution, which blocked GTP hydrolysis and thus GTP- and dynamindependent endocytosis (compare Fig. 1, C and $E$ ) [for detail, see Xu et al. (2008); see also supplemental information IV, available at www.jneurosci.org as supplemental material]. In this condition, the RRP replenishment after a 20 ms depolarization could be fit well with Equation 1 with $A_{1}=0.7, \tau_{1}=0.24 \mathrm{~s}, A_{2}=0.3, \tau_{2}=7.2 \mathrm{~s}$ (Fig. $1 E, F)$. These fitting parameters and the fitted curve (Fig. $1 F$, solid curve) were similar to those obtained in control (Fig. $1 D$ or F, dotted curve), indicating that slow endocytosis did not directly contribute to either the rapid or the slow component of the RRP replenishment.

\section{Rapid endocytosis does not recycle vesicles within the RRP}

To determine whether rapid endocytosis recycles vesicles within the RRP, we induced rapid endocytosis with 10 pulses of 20 ms depolarization at 10 or $1 \mathrm{~Hz}$ (Wu et al., 2005). The capacitance jump after 10 depolarizing pulses at 10 $\mathrm{Hz}$ was $1260 \pm 72 \mathrm{fF}(n=11)$ (Fig. $2 A)$, which was followed by a biexponential capacitance decay reflecting rapid $(\tau=1.7 \pm 0.4 \mathrm{~s}$, $31 \pm 3 \%, n=11)$ and slow $(\tau=19 \pm 3 \mathrm{~s}, n=11)$ component of endocytosis (Fig. 2A, right) [for detail, see Wu et al. (2005)]. Two pieces of evidence suggest that this rapid endocytosis did not recycle vesicles within the RRP.

First, the amplitude of rapid endocytosis $(465 \pm 15 \mathrm{fF}, n=11)$ (Fig. $2 A)$ was similar to the RRP size $(459 \pm 29 \mathrm{fF}, n=28)$ (Fig. $1 A, B)$. If rapid endocytosis recycles vesicles within the RRP, the RRP replenishment should be significantly sped up. To test this prediction, we applied a testing $20 \mathrm{~ms}$ depolarization at various $\Delta t$ after the conditioning 10 depolarizing pulses at $10 \mathrm{~Hz}$. The capacitance jump induced by the testing pulse, which reflected the RRP replenishment, was fitted well with Equation 1 with $A_{1}=0.33, \tau_{1}=$ $0.38 \mathrm{~s}, A_{2}=0.67, \tau_{2}=7.8 \mathrm{~s}$ (Fig. $2 A, B$ ). Compared with the fitted replenishment curve after a $20 \mathrm{~ms}$ depolarization (same as Fig. $1 D$ ), $A_{1}$ (rapid component of replenishment) decreased, $A_{2}$ (slow component of replenishment) increased, but the time constants $\left(\tau_{1}, \tau_{2}\right)$ were similar. These differences were evident when comparing individual data points. For example, at $\Delta t$ of 0.5 and $2 \mathrm{~s}$, the $\Delta C_{\mathrm{m}}$ (induced by a $20 \mathrm{~ms}$ depolarization) was $61 \pm$ $4 \%(n=11)$ and $76 \pm 5 \%(n=5)$ of control, respectively, after a 20 ms depolarization, but only $28 \pm 4 \%(n=12, p<0.01)$ and $48 \pm 6 \%(n=5, p<0.01)$ after 10 depolarizing pulses at $10 \mathrm{~Hz}$. Similar slow down of the RRP replenishment was obtained after
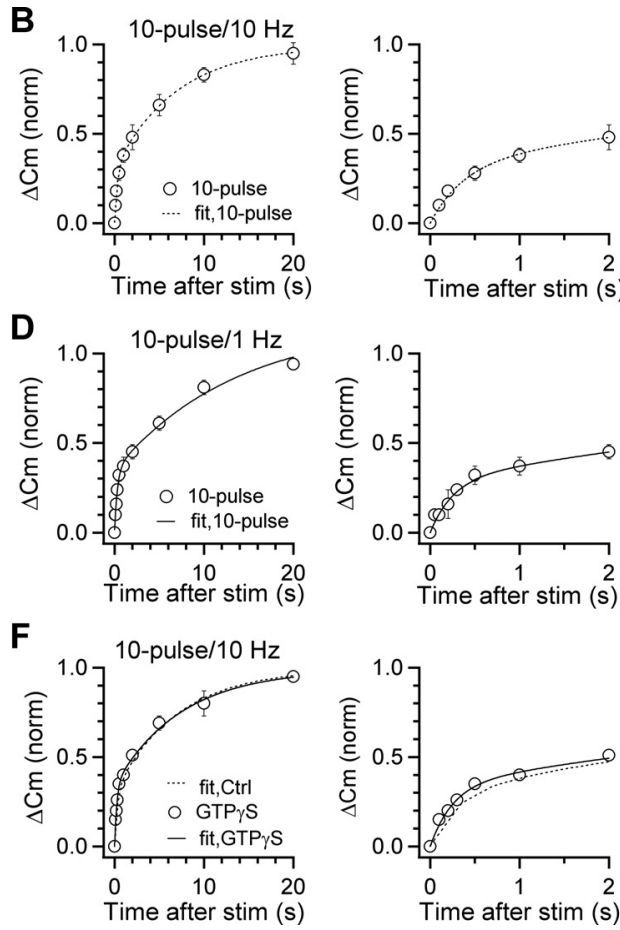

Figure 2. Rapid endocytosis does not recycle vesicles within the RRP. $\boldsymbol{A}$, Sampled $C_{\mathrm{m}}$ induced by a 20 ms depolarization (arrow) applied at 0.5 (left) or $20 \mathrm{~s}$ (right) after a conditioning stimulus composed of 10 pulses of $20 \mathrm{~ms}$ depolarization at $10 \mathrm{~Hz}$ ( $\boldsymbol{A}$, bar). $\boldsymbol{B}$ $\Delta C_{\mathrm{m}}$ induced by a $20 \mathrm{~ms}$ depolarization applied at various intervals after a conditioning stimulus composed of 10 pulses of $20 \mathrm{~ms}$ atization at $10 \mathrm{~Hz}$. Data (circles, $n=5-12$ ) were normalized to the $\Delta C_{\mathrm{m}}$ induced by a $20 \mathrm{~ms}$ depolarization applied at $>30$ Endocytosis after this stimulus was biexponential with time constants of $\sim 17 \mathrm{~s}$ and $\sim 19$ s, respectively. $C$, Similarto $A$ and $B$

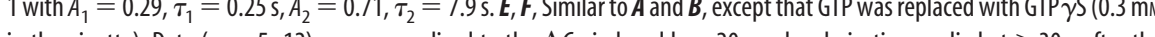
conditioning stimulus and fit with Equation 1 with $A_{1}=0.36, \tau_{1}=0.25 \mathrm{~s}, A_{2}=0.64, \tau_{2}=7.7 \mathrm{~s}(\boldsymbol{F}$, solid curve). The fit curve in control ( $0.3 \mathrm{~mm}$ GTP, dotted curve in $\boldsymbol{B}$ ) is also shown (dotted curve in $\boldsymbol{F}$ ). stim, Stimulation.

10 pulses of $20 \mathrm{~ms}$ depolarization at $1 \mathrm{~Hz}$ (Fig. 2C,D), during which vesicles equivalent to approximately six times the RRP size were released and about half of released vesicles (approximately three times the RRP size) were retrieved rapidly (Fig. 2C) [for detail, see Wu et al. (2005), their Fig. 1D]. The time course of the RRP replenishment after 10 pulses of $20 \mathrm{~ms}$ depolarization at 1 $\mathrm{Hz}$ (Fig. 2D) was similar to that after 10 pulses of $20 \mathrm{~ms}$ depolarization at $10 \mathrm{~Hz}$. A modest inactivation of calcium current was observed during the 10-pulse train, but the current was still sufficient to release all vesicles in the RRP (supplemental information III, available at www.jneurosci.org as supplemental material). In summary, the occurrence of rapid endocytosis after 10 depolarizing pulses at 10 or $1 \mathrm{~Hz}$ was not accompanied by a speeding up, but a slowing down of the RRP replenishment, arguing against the hypothesis that rapid endocytosis recycles vesicles within the RRP.

Second, we blocked both rapid and slow endocytosis by including GTP $\gamma \mathrm{S}(0.3 \mathrm{~mm}$ ) in the pipette solution (Fig. $2 \mathrm{E}$ ) [for detail, see Xu et al. (2008)] and measured the capacitance jump induced by a testing $20 \mathrm{~ms}$ depolarization applied at various intervals after the conditioning 10 pulses of $20 \mathrm{~ms}$ depolarization at $10 \mathrm{~Hz}$. We limited our stimulation so that the net capacitance increase did not exceed $\sim 4 \mathrm{pF}$, above which a GTP-independent form of endocytosis could be activated (Xu et al., 2008). We also monitored the capacitance trace to ensure that endocytosis was abolished. In this condition, the capacitance jump induced by the 
testing $20 \mathrm{~ms}$ pulse, which reflected the RRP replenishment, was fitted well with Equation 1 with $A_{1}=0.36, \tau_{1}=0.25 \mathrm{~s}, A_{2}=0.64$, $\tau_{2}=7.7 \mathrm{~s}$ (Fig. $2 \mathrm{~F}$, solid curve). The fitted curve and the fitted parameters were similar to those obtained in control $(0.3 \mathrm{mM}$ GTP) (Fig. $2 F$, dotted curve). At $\Delta t$ of 0.5 and $2 \mathrm{~s}$, the RRP recovered to $22 \pm 6 \%(n=6)$ and $50 \pm 3 \%(n=7)$ (Fig. $2 F)$, respectively, which were similar to control ( $0.5 \mathrm{~s}: 28 \pm 4 \%, n=$ $12, p>0.46 ; 2$ s: $48 \pm 6 \%, n=5, p>0.80$ ) (Fig. $2 B$ ). Thus, block of both rapid and slow endocytosis did not affect the RRP replenishment after 10 pulses of $20 \mathrm{~ms}$ depolarization at $10 \mathrm{~Hz}$, a stimulus which released vesicles equivalent to $\sim 3$ times the RRP size.

We also replaced GTP with GDP $\beta S(0.3 \mathrm{~mm})$ to block endocytosis and repeated experiments shown in Figure 2, E and F. In the presence of GDP $\beta$, at 0.5 and $2 \mathrm{~s}$ after 10 pulses of $20 \mathrm{~ms}$ depolarization at $10 \mathrm{~Hz}$, the $\Delta C_{\mathrm{m}}$ induced by the testing $20 \mathrm{~ms}$ depolarization recovered to $30 \pm 3 \%(n=7)$ and $53 \pm 4 \%(n=$ 7 ), respectively, which were similar to those $(28 \pm 4 \%, n=12$; $48 \pm 7 \%, n=6)$ obtained in the absence of GDP $\beta$ S ( 0.3 mM GTP; $p>0.3$ ) (supplemental information $\mathrm{V}$, available at www. jneurosci.org as supplemental material). Thus, block of both rapid and slow endocytosis with either GTP $\gamma \mathrm{S}$ or GDP $\beta$ S did not affect the RRP replenishment time course.

Together, our results suggest that neither rapid nor slow endocytosis recycle vesicles within the RRP. The recycling pool into which rapid endocytosis retrieves vesicles must be larger than $\sim 3$ times the RRP size, because block of endocytosis did not affect the RRP replenishment after 10 depolarizing pulses at $10 \mathrm{~Hz}$ that released vesicles equivalent to $\sim 3$ times the RRP size.

Our results that rapid RRP replenishment did not require rapid endocytosis (Fig. 1) and was not affected by the block of rapid endocytosis (Fig. 2) strongly argue against the hypothesis that rapid endocytosis recycles vesicles rapidly within the RRP. Could rapid endocytosis make a minor contribution to the rapid RRP replenishment? If so, it predicts that more rapid endocytosis should speed up the RRP replenishment. Approximately 1 and 3 times the RRP size of vesicles were rapidly retrieved after 10 pulses of $20 \mathrm{~ms}$ depolarization at 10 and $1 \mathrm{~Hz}$, respectively. However, the RRP replenishment time course was similar after these two stimuli (Fig. $2 B, D$ ). Furthermore, the rapid component of the RRP replenishment in the absence of rapid endocytosis (after a $20 \mathrm{~ms}$ depolarization) (Fig. $1 D$ ) was larger than that in the presence of rapid endocytosis (after 10 pulses of $20 \mathrm{~ms}$ depolarization at $1-10 \mathrm{~Hz}$ ) (Fig. $2 B, D$ ). These results strongly argue against any detectable contribution of rapid endocytosis to the RRP replenishment.

\section{Discussion}

The present work revealed that activation of rapid endocytosis was not accompanied by faster RRP replenishment and that block of both slow and rapid endocytosis did not affect the rate of the RRP replenishment. These results provided the first set of experimental evidence, suggesting that both rapid and slow endocytosis did not recycle vesicles within the RRP but within a large recycling pool more than $\sim 3$ times the RRP size. Thus, the widely held view that rapid endocytosis provides a fast local route for recycling vesicles within the RRP is incorrect, at least at the calyx of Held synapse. This finding is likely to apply beyond the calyx of Held synapse, because the RRP recovered from depletion in $\sim 30-40$ s in the absence of rapid endocytosis at goldfish ribbontype synapses, although whether rapid endocytosis affects the rate of the RRP replenishment at this synapse was not examined (von Gersdorff and Matthews, 1997).
At hippocampal synapses where the debate about the existence of kiss-and-run is intense ( $\mathrm{He}$ and $\mathrm{Wu}, 2007)$, rapid kissand-run, which must involve rapid endocytosis, has been suggested to recycle vesicles within the RRP (Pyle et al., 2000; Sara et al., 2002; Zhang et al., 2009). This seems in conflict with the present work. Tissue specificity could provide an explanation for this apparent conflict, considering that calyces are much larger than conventional boutons. However, we consider tissue specificity an unlikely explanation, because calyces are similar to conventional boutons in many aspects. For example, similar to conventional active zones, the calyx releases small clear-core vesicles; an active zone is associated with $\sim 100-200$ vesicles (Harata et al., 2001; Sätzler et al., 2002); release is mostly controlled by P/Q-type calcium channels (Wu et al., 1999; Iwasaki et al., 2000); a train of high frequency firing causes short-term depression (von Gersdorff and Borst, 2002); endocytosis is slow in many stimulation conditions but could also be fast (Wu et al., 2005). The calyx is often considered a special nerve terminal releasing much more vesicles than conventional boutons during an action potential. Such a consideration is not entirely appropriate, because it does not take into account of the fundamental release property per active zone or release site. A calyx contains $\sim 550$ active zones and an action potential releases $\sim 50-500$ vesicles during an action potential (Borst et al., 1995; Wu et al., 1999). Thus, the release probability per active zone during an action potential may range from $\sim 0.09-0.91$, which overlaps with the release probability of most conventional boutons (Zucker and Regehr, 2002). An action potential releases $\sim 5 \%$ of the RRP vesicles in calyces (Schneggenburger et al., 2002; Xu and Wu, 2005), similar to some of the conventional boutons (Zucker and Regehr, 2002). Thus, tissue specificity is an unlikely explanation for the apparent discrepancy between our results and those obtained in hippocampal synapses.

Our finding that rapid endocytosis did not recycle vesicles within the RRP calls for reconsideration of the function and the underlying mechanism of rapid endocytosis. We consider three possibilities. First, rapid endocytosis may still reflect kiss-andrun but does not recycle within the RRP. This possibility requires that after kiss-and-run, the vesicle must leave the RRP immediately, which is logically unlikely to occur. Second, rapid endocytosis follows full collapse fusion just like slow endocytosis but retrieves vesicles with a higher speed. Third, rapid endocytosis may reflect bulk endocytosis, as has been proposed in ribbontype synapses (Llobet et al., 2003). The present work points to the need to distinguish these possibilities in the future, considering that rapid endocytosis is widely observed and thus may play an important role in maintaining exocytosis in neurons and non-neuronal secretory cells in various stimulation conditions ( $\mathrm{Wu}, 2004)$.

Although rapid endocytosis does not recycle vesicles within the RRP, compared with slow endocytosis, rapid endocytosis can still provide a faster speed in replenishing the recycling vesicle pool. This function may be particularly important during prolonged high frequency firing that may deplete vesicles in the recycling pool. In support of this possibility, rapid endocytosis is activated by high frequency firing (Wu et al., 2005), which occurs in physiological conditions at calyces and other neurons (von Gersdorff and Borst, 2002). Furthermore, high frequency firing may induce fusion of many vesicles at release sites and thus may disrupt the normal structure of release sites. We suggest that rapid endocytosis activated during high frequency firing participates in maintaining the normal structure of nerve terminals, including active zones, by clearing fused vesicle membrane from active zones. 
We found that the RRP replenishment time course was slowed down by more intense stimulation (Figs. 1D, 2B,D). This observation is surprising, given that the RRP replenishment is calcium/calmodulin-dependent and that more intense stimulation presumably should raise the intracellular calcium concentration thus activate calmodulin to a higher level (Dittman and Regehr, 1998; Wang and Kaczmarek, 1998; Sakaba and Neher, 2001). Thus, a mechanism other than the calcium/ calmodulin-dependent mechanism must be involved in controlling the RRP replenishment. It would be of great interest to examine this possibility in the future, which may contribute to the generation of short-term plasticity during intense firing.

\section{References}

Albillos A, Dernick G, Horstmann H, Almers W, Alvarez de Toledo G, Lindau M (1997) The exocytotic event in chromaffin cells revealed by patch amperometry. Nature 389:509-512.

Aravanis AM, Pyle JL, Tsien RW (2003) Single synaptic vesicles fusing transiently and successively without loss of identity. Nature 423:643-647.

Artalejo CR, Henley JR, McNiven MA, Palfrey HC (1995) Rapic endocytosis coupled to exocytosis in adrenal chromaffin cells involves $\mathrm{Ca}^{2+}, \mathrm{GTP}$, and dynamin but not clathrin. Proc Natl Acad Sci U S A 92:8328-8332.

Borst JG, Helmchen F, Sakmann B (1995) Pre- and postsynaptic whole-cell recordings in the medial nucleus of the trapezoid body of the rat. J Physiol 489:825-840.

Dittman JS, Regehr WG (1998) Calcium dependence and recovery kinetics of presynaptic depression at the climbing fiber to Purkinje cell synapse. J Neurosci 18:6147-6162.

Fesce R, Grohovaz F, Valtorta F, Meldolesi J (1994) Neurotransmitter release, fusion or 'kiss and run'? Trends Cell Biol 4:1-4.

Gillis KD (1995) Techniques for membrane capacitance measurements. In: Single-channel recording (Sakmann B, Neher E, eds), pp 155-198. New York: Plenum.

Granseth B, Odermatt B, Royle SJ, Lagnado L (2006) Clathrin-mediated endocytosis is the dominant mechanism of vesicle retrieval at hippocampal synapses. Neuron 51:773-786.

Hallermann S, Pawlu C, Jonas P, Heckmann M (2003) A large pool of releasable vesicles in a cortical glutamatergic synapse. Proc Natl Acad Sci U S A 100:8975-8980.

Harata N, Pyle JL, Aravanis AM, Mozhayeva M, Kavalali ET, Tsien RW (2001) Limited numbers of recycling vesicles in small CNS nerve terminals: implications for neural signaling and vesicular cycling. Trends Neurosci 24:637-643.

He L, Wu LG (2007) The debate on the kiss-and-run fusion at synapses. Trends Neurosci 30:447-455.

He L, Wu XS, Mohan R, Wu LG (2006) Two modes of fusion pore opening revealed by cell-attached recordings at a synapse. Nature 444:102-105.

He Z, Fan J, Kang L, Lu J, Xue Y, Xu P, Xu T, Chen L (2008) $\mathrm{Ca}^{2+}$ triggers a novel clathrin-independent but actin-dependent fast endocytosis in pancreatic beta cells. Traffic 9:910-923.

Hsu S-F, Jackson MB (1996) Rapid exocytosis and endocytosis in nerve terminals of the rat posterior pituitary. J Physiol 492:539-553.

Iwasaki S, Momiyama A, Uchitel OD, Takahashi T (2000) Developmental changes in calcium channel types mediating central synaptic transmission. J Neurosci 20:59-65.

Klyachko VA, Jackson MB (2002) Capacitance steps and fusion pores of small and large-dense-core vesicles in nerve terminals. Nature 418:89-92.
Lindau M, Neher E (1988) Patch-clamp techniques for time-resolved capacitance measurements in single cells. Pflugers Arch 411:137-146.

Llobet A, Beaumont V, Lagnado L (2003) Real-time measurement of exocytosis and endocytosis using interference of light. Neuron 40:1075-1086.

Pyle JL, Kavalali ET, Piedras-Rentería ES, Tsien RW (2000) Rapid reuse of readily releasable pool vesicles at hippocampal synapses. Neuron 28:221-231.

Sakaba T, Neher E (2001) Calmodulin mediates rapid recruitment of fastreleasing synaptic vesicles at a calyx-type synapse. Neuron 32:1119-1131.

Sara Y, Mozhayeva MG, Liu X, Kavalali ET (2002) Fast vesicle recycling supports neurotransmission during sustained stimulation at hippocampal synapses. J Neurosci 22:1608-1617.

Sätzler K, Söhl LF, Bollmann JH, Borst JG, Frotscher M, Sakmann B, Lübke JH (2002) Three-dimensional reconstruction of a calyx of Held and its postsynaptic principal neuron in the medial nucleus of the trapezoid body. J Neurosci 22:10567-10579.

Schneggenburger R, Sakaba T, Neher E (2002) Vesicle pools and short-term synaptic depression: lessons from a large synapse. Trends Neurosci 25:206-212.

Sun JY, Wu LG (2001) Fast kinetics of exocytosis revealed by simultaneous measurements of presynaptic capacitance and postsynatpic currents at a central synapse. Neuron 30:171-182.

Sun JY, Wu XS, Wu LG (2002) Single and multiple vesicle fusion induce different rates of endocytosis at a central synapse. Nature 417:555-559.

Sun JY, Wu XS, Wu W, Jin SX, Dondzillo A, Wu LG (2004) Capacitance measurements at the calyx of Held in the medial nucleus of the trapezoid body. J Neurosci Methods 134:121-131.

Taschenberger H, Leão RM, Rowland KC, Spirou GA, von Gersdorff H (2002) Optimizing synaptic architecture and efficiency for highfrequency transmission. Neuron 36:1127-1143.

von Gersdorff H, Borst JG (2002) Short-term plasticity at the calyx of held. Nat Rev Neurosci 3:53-64.

von Gersdorff H, Matthews G (1994) Dynamics of synaptic vesicle fusion and membrane retrieval in synaptic terminals. Nature 367:735-739.

von Gersdorff H, Matthews G (1997) Depletion and replenishment of vesicle pools at a ribbon-type synaptic terminal. J Neurosci 17:1919-1927.

Wang LY, Kaczmarek LK (1998) High-frequency firing helps replenish the readily releasable pool of synaptic vesicles. Nature 394:384-388.

Wu LG (2004) Kinetic regulation of vesicle endocytosis at synapses. Trends Neurosci 27:548-554.

Wu LG, Borst JG (1999) The reduced release probability of releasable vesicles during recovery from short-term synaptic depression. Neuron 23:821-832.

Wu LG, Borst JG, Sakmann B (1998) R-type $\mathrm{Ca}^{2+}$ currents evoke transmitter release at a rat central synapse. Proc Natl Acad Sci U S A 95:4720-4725.

Wu LG, Westenbroek RE, Borst JG, Catterall WA, Sakmann B (1999) Calcium channel types with distinct presynaptic localization couple differentially to transmitter release in single calyx-type synapses. J Neurosci 19:726-736.

Wu W, Xu J, Wu XS, Wu LG (2005) Activity-dependent acceleration of endocytosis at a central synapse. J Neurosci 25:11676-11683.

$\mathrm{Xu} \mathrm{J,} \mathrm{Wu} \mathrm{LG} \mathrm{(2005)} \mathrm{The} \mathrm{decrease} \mathrm{in} \mathrm{the} \mathrm{presynaptic} \mathrm{calcium} \mathrm{current} \mathrm{is} \mathrm{a}$ major cause of short-term depression at a calyx-type synapse. Neuron 46:633-645.

Xu J, McNeil B, Wu W, Nees D, Bai L, Wu LG (2008) GTP-independent rapid and slow endocytosis at a central synapse. Nat Neurosci 11:45-53.

Zhang Q, Li Y, Tsien RW (2009) The dynamic control of kiss-and-run and vesicular reuse probed with single nanoparticles. Science 323:1448-1453.

Zucker RS, Regehr WG (2002) Short-term synaptic plasticity. Annu Rev Physiol 64:355-405. 